\title{
Effects of Magnesium Chloride on Rocuronium-induced Neuromuscular Blockade and Sugammadex Reversal in the Isolated Rat Phrenic Nerve-hemidiaphragm Preparation
}

\author{
Sung T.-Y. ${ }^{1}$, Cho C.-K. ${ }^{1}$, Shin Y.S. ${ }^{2}$, Yang H.S. ${ }^{3}$
}

${ }^{1}$ Konyang University Hospital, Konyang University College of Medicine, Dept of Anaesthesiology \& Pain

Medicine, Daejeon, Korea, Republic of, ${ }^{2}$ Chungnam National University School of Medicine, Dept of Anaesthesiology \& Pain Medicine, Daejeon, Korea, Republic of, ${ }^{3}$ Asan Medical Center, College of medicine, University of Ulsan, Dept of Anaesthesiology \& Pain Medicine, Seoul, Korea, Republic of

\section{Background}

Magnesium potentiates the effect of nondepolarizing muscle relaxants. However, studies which have been conducted by using magnesium chloride $\left(\mathrm{MgCl}_{2}\right)$ are rare. Sugammadex reverses neuromuscular block by steroidal nondepolarizing muscle relaxants. The purpose of this study is to investigate effects of $\mathrm{MgCl}_{2}$ on rocuronium-induced neuromuscular blockade and its reversal by sugammadex.

\section{Materials and Methods}

Left phrenic nerve-hemidiaphragms from 40 SpragueDawly rats were randomly allocated to four groups ( $1 \mathrm{mM}, 2 \mathrm{mM}, 3 \mathrm{mM}$ and $4 \mathrm{mM} \mathrm{MgCl}{ }_{2}$ group, each $\mathrm{n}=10$ ). Rocuronium was administered cumulatively until the first twitch (T1) of train-of-four (TOF) completely disappeared for obtaining the effective concentration (EC) of rocuronium in each group. Thereafter, equimolar sugammadex was administered and recovery of $\mathrm{T} 1$ height and TOF ratio were measured for 30 minutes.

\section{Results}

Table 1. Comparisons of effective concentration of rocuronium

\begin{tabular}{lcccc}
\hline & \multicolumn{4}{c}{ Concentration of $\mathrm{MgCl}_{2}$} \\
\cline { 2 - 5 } & $1 \mathrm{mM}$ & $2 \mathrm{mM}$ & $3 \mathrm{mM}$ & $4 \mathrm{mM}$ \\
\hline $\mathrm{EC}_{5}(\mu \mathrm{g} / \mathrm{ml})$ & $3.7 \pm 1.0$ & $3.2 \pm 0.6$ & $2.4 \pm 0.6^{*}$ & $2.3 \pm 0.3^{*}, \dagger$ \\
$\mathrm{EC}_{50}(\mu \mathrm{g} / \mathrm{ml})$ & $7.8 \pm 1.1^{\dagger}$ & $5.9 \pm 0.6^{*}$ & $4.5 \pm 0.8^{*, \dagger}$ & $4.3 \pm 0.4^{*}, \dagger$ \\
$\mathrm{EC}_{90}(\mu \mathrm{g} / \mathrm{ml})$ & $11.4 \pm 1.3^{\dagger}$ & $8.4 \pm 0.5^{*}$ & $6.5 \pm 1.2^{*, \dagger}$ & $6.2 \pm 0.7^{*}, \dagger$ \\
$\mathrm{EC}_{95}(\mu \mathrm{g} / \mathrm{ml})$ & $12.1 \pm 1.3^{\dagger}$ & $9.0 \pm 0.5^{*}$ & $7.0 \pm 1.2^{*}, \dagger$ & $6.7 \pm 0.7^{*}, \dagger$ \\
\hline
\end{tabular}

Fig. 1. The concentration - response curves of rocuronium

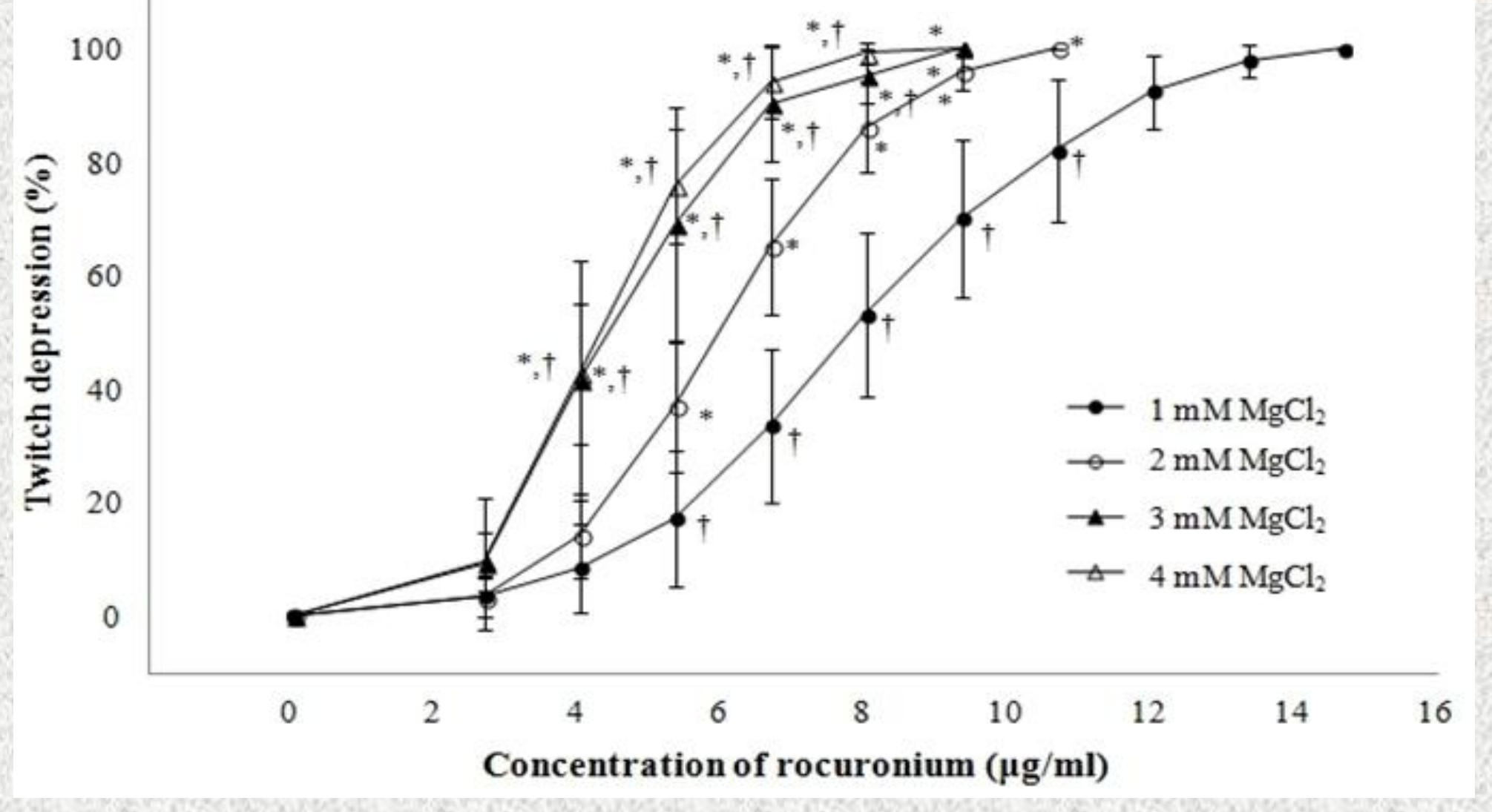

Table 2. Recovery data after sugammadex administration

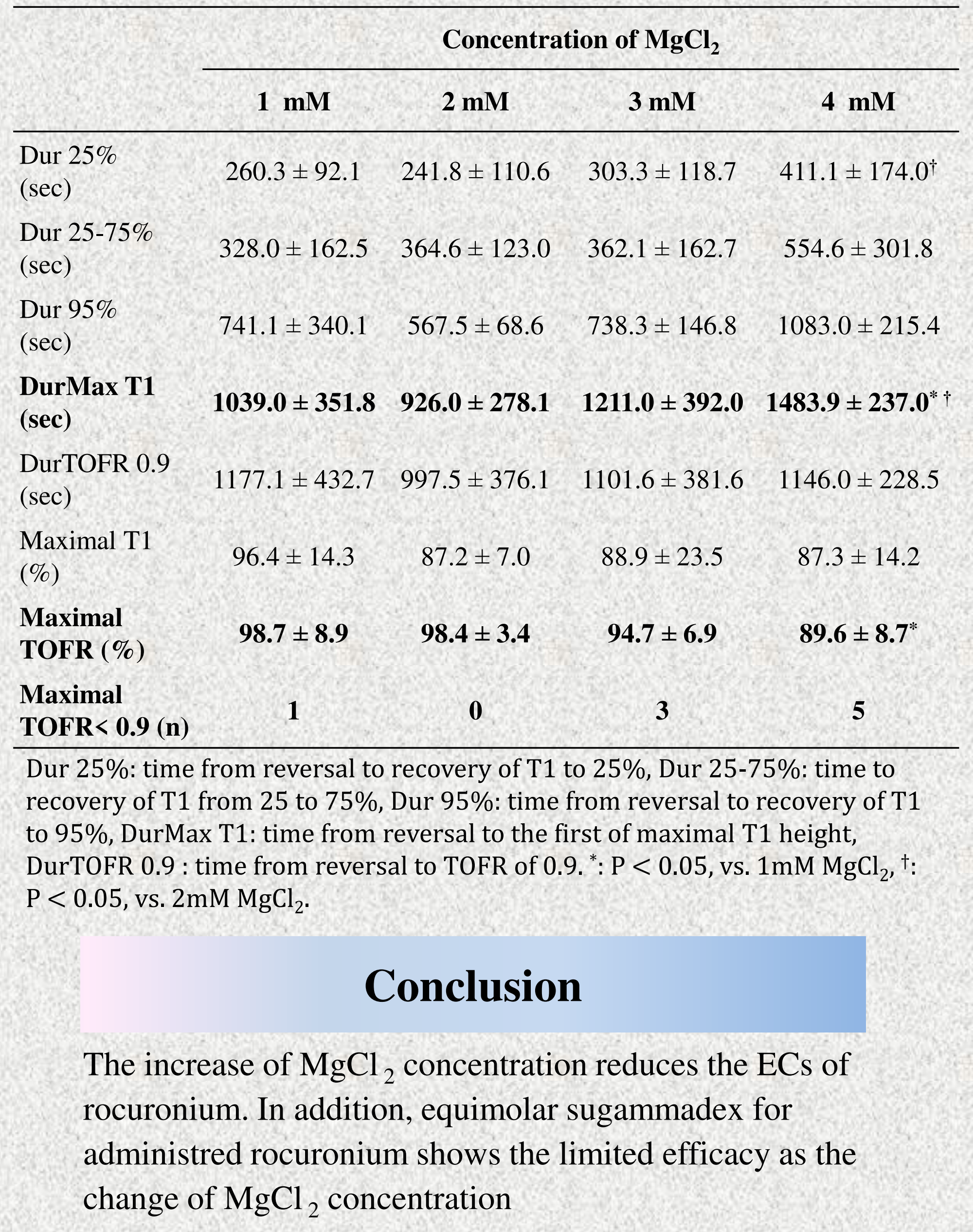

